\title{
ИСПОЛЬЗОВАНИЕ МЕХАНИЗМА ГОСУДАРСТВЕННО-ЧАСТНОГО ПАРТНЕРСТВА ДЛЯ ПРИВЛЕЧЕНИЯ ИНВЕСТИЦИОННОГО КАПИТАЛА В МЯСНОЕ СКОТОВОДСТВО
}

\author{
(c) 2021 Мазлоев Виталий Зелимханович \\ доктор экономических наук, профессор, \\ главный научный сотрудник ФГБНУ ФНЦ ВНИИЭСХ, \\ Заслуженный деятель науки РФ, Россия, Москва \\ E-mail: mazloevv@mail.ru \\ (c) 2021 Хаирбеков Алихан Уружалиевич \\ кандидат экономических наук, \\ ведущий научный сотрудник ФГБНУ ФНЦ ВНИИЭСХ, Россия, Москва \\ E-mail:156237@gmail.com
}

На сегодняшний день отечественный агропромышленный комплекс в целом и практически все его составляющие подкомплексы испытывают недостаток инвестиций, необходимых для своего развития на качественно новой технико-технологической основе. В этом плане одной из важнейших подотраслей является производство мясной продукции.

В статье предлагается с целью активизации инвестиционного процесса в мясной подкомплекс эффективно использовать механизм государственно-частного партнерства (ГЧП), позволяющий привлечь и сосредоточить инвестиционный капитал.

Ключевые слова: государственно-частное партнерство, инвестиционный капитал, инвестирование, мясное скотоводство, импортозамещение, импорт, экспорт, продовольственная безопасность, агропромышленное производство.

Введение. Опыт развития мясного скотоводства подтверждает объективную необходимость государственной поддержки данной отрасли в силу ее большой значимости для обеспечения продовольственной безопасности страны, а также в связи со специфическими особенностями, обуславливающими его низкую конкурентоспособность по сравнению с мясом других видов животных, тем более на мировом рынке мяса. Как следует из Доктрины продовольственной безопасности РФ, отечественное производство мяса КРС должно достигнуть до 85\% общего потребления [1].

Производство мяса КРС в нашей стране осуществляется преимущественно на базе стада животных молочных пород. При этом отечественная говядина имеет низкую конкурентоспособность по сравнению с аналогичной продукцией зарубежных производителей, использующих специализированный скот мясных пород, имеющий преимущества по продуктивности животных и качеству продукции. Мировая практика показывает, что с ростом продуктивности коров молочных пород их поголовье сокращается, что снижает ресурсный потенциал производства говядины, восстановление которого осуществляется за счет наращивания поголовья КРС мясных пород [2].

Результаты. В результате изучения отечественного опыта развития мясного скотоводства нами установлено, что основными направлениями государственной поддержки производства продукции исследуемой отрасли являются предоставление средств на снижение цены ресурсов, используемых сельскохозяйственными товаропроизводителями, а также прямые выплаты на единицу реализованной продукции, на содержание 1 головы крупного рогатого скота и прочее. Существенную роль играют и косвенная поддержка (например, меры таможенно-тарифного регулирования), а также опосредованная, выражающаяся в осуществлении организационноэкономических мероприятий, в частности, это проведение научных исследований, развитие инфраструктуры, которые, в свою очередь, согласно правилам ВТО относятся к мерам зеленой корзины и могут применяться без ограничений.

Вместе с тем, в рамках Государственной программы развития сельского хозяйства с 2013 г. предусматривались субсидии на развитие пле- 
менной базы крупного рогатого скота мясных пород, поддержку экономически значимых региональных программ, компенсацию части процентной ставки по инвестиционным кредитам и (с 2016 г.) субсидии на содержание товарного маточного поголовья крупного рогатого скота мясного направления. С 2017 г. механизм предоставления субсидий был изменен, в частности, была проведена консолидация направлений государственной поддержки и введена единая субсидия для субъектов России, самостоятельно распределяющих эти средства на основе приоритетных направлений.

Несмотря на реализацию Государственная программа развития сельского хозяйства и регулирования рынков сельскохозяйственной продукции, сырья и продовольствия на 2008-2012 гг. и 2013-2018 гг., производство отечественного мяса КРС снижалось и только в 2018-2019 гг. негативная тенденция была приостановлена (рисунок 1).

Этому способствовало увеличение поголовья крупного рогатого скота мясного направления в сельскохозяйственных организациях и КФХ, включая ИП (табл. 1) почти на 1 млн. голов за 2013-2019 гг.

Следует отметить, что с 2020 г. введены новые правила субсидирования АПК, в частности, вместо единой региональной субсидии, несвязанной погектарной поддержки и субсидии на литр молока предусмотрены компенсирующая и стимулирующая субсидия. При этом развитие специализированного мясного скотоводства выбрано одним из приоритетных направления развития АПК России. В рамках Государственной программы за 2013-2019 гг. в России вве-

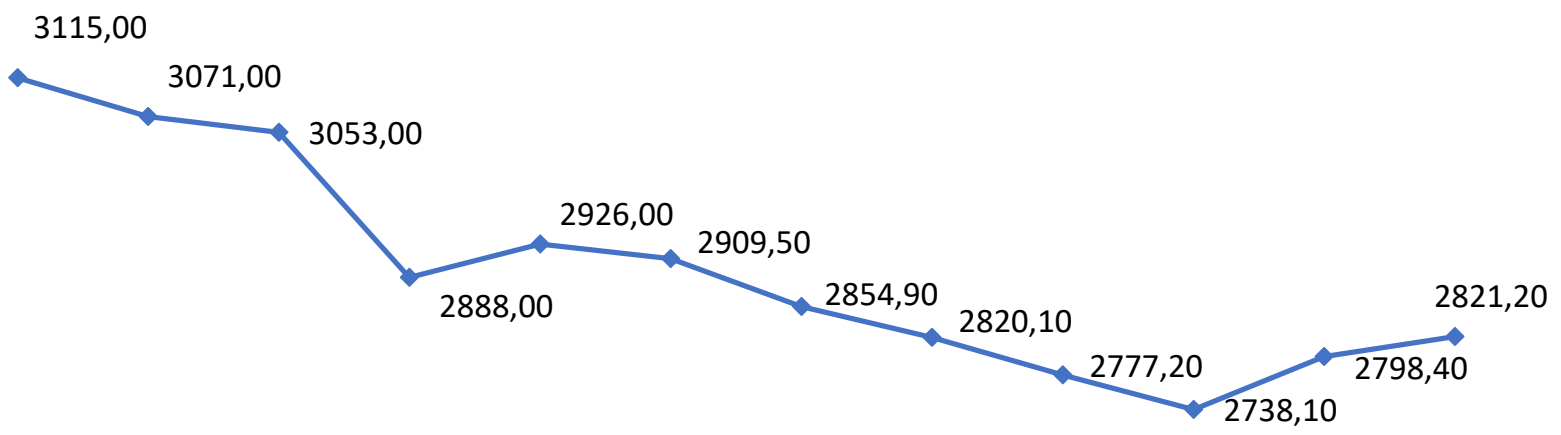

$\begin{array}{llllllllllll}2008 & 2009 & 2010 & 2011 & 2012 & 2013 & 2014 & 2015 & 2016 & 2017 & 2018 & 2019\end{array}$

Рисунок 1. Производство мяса крупного рогатого скота на убой (в живом весе), тыс. тонн

Таблица 1. Поголовье КРС специализированных и мясных пород за годы реализации Государственной программы развития мясного скотоводства 2013-2019 гг., тыс. голов

\begin{tabular}{|c|c|c|c|}
\hline \multirow{2}{*}{ Годы } & \multicolumn{3}{|c|}{$\begin{array}{c}\text { Поголовье КРС специализированных мясных пород и помесного скота } \\
\text { в сельскохозяйственных организациях и КФХ, включая ИП, тыс. голов }\end{array}$} \\
\cline { 2 - 4 } & План & Фактически & Темп роста \\
\hline 2013 & 2160,0 & 2185,2 & 101,2 \\
\hline 2014 & 2340,0 & 2362,2 & 100,9 \\
\hline 2015 & 2525,0 & 2575,2 & 96,0 \\
\hline 2016 & 2720,0 & 2610,4 & 106,9 \\
\hline 2017 & 2550,0 & 2726,1 & 106,6 \\
\hline 2018 & 2700,0 & 2877,9 & 107,4 \\
\hline 2019 & 2800,0 & 3006,6 & \\
\hline
\end{tabular}

Источник: по данным МСХ РФ 
дено 459 объектов мясного скотоводства, в том числе 311 новых, на которых произведено 73,2 тыс. т. мяса крупного рогатого скота на убой в живом весе. В 2016 г. в сфере мясного скотоводства Минсельхоз России просубсидировал 392 инвестиционных кредита. Было отобрано также 52 инвестиционных проекта предприятий мясного скотоводства, крупнейшими из которых стали ООО «Брянская мясная компания» (Брянская область), ООО «БифАрт» (Республика Калмыкия), ООО «Заречное» (Воронежская область) и ООО «Калининградская мясная компания» (Калининградская область) [3].

По нашим данным в Российской Федерации на конец 2019 г. численность товарного поголовья коров специализированных мясных пород в СХО, К(Ф)Х, включая ИП, составила 959,97 тыс. голов, что на 59,8 тыс. голов, или 8,2\%, больше, чем в 2018 г. Такие показатели свидетельствуют о создании базы для дальнейшего развития отечественного мясного скотоводства.

Всего за 2013-2019 гг. введено 311 новых и модернизировано 148 объектов мясного скотоводства. За 7 лет дополнительное производство КРС на убой на этих объектах составило 73,2 тыс. т. За это время производство дополнительных объемов специализированного мясного и поместного КРС на убой на вновь построенных и модернизированных объектах по федеральным округам осуществлялось неравномерно. В отчетном году было введено 29 новых, модернизированных и реконструированных объектов мясного скотоводства, которые позволили дополнительно произвести 1,3 тыс. т. КРС на убой (в живом весе).

В 2019 г. поголовье КРС специализированных мясных пород и помесного скота в хозяйствах всех категорий составило около 3,85 млн. голов и увеличилось относительно 2013 г. на 33,8\%, или 0,97 млн. голов. Доля специализированного мясного и помесного скота составляет 21,2\% общего поголовья КРС.

Производство КРС на убой в 2019 г. увеличилось в 40 регионах, сократилось в 17. Лидерами по наращиванию производства КРС на убой являются Орловская область -32 тыс. т. (в 2 раза), Республика Калмыкия - 4 тыс. т. (20,4\%), Самарская -2,9 тыс. т. (на 24,4\%), Смоленская - 2,6 тыс. т. (в 3 раза) области, Республика Дагестан - 3,2 тыс. т. (на 21,3\%), Ростовская - 1,7 тыс. т. (14\%), Брянская - 1,5 тыс. т. (3,1\%) области.[4]

Надо сказать, что такая благоприятная си- туация и достаточно динамичная тенденция в первую очередь обусловлена ростом численности поголовья мясного скота, кроме того, проведенные нами расчёты показывают наиболее быстрый темп роста затрат на содержание основных средств нежели оплаты труда, то есть это дает основание говорить о высоком уровне его технической оснащенности, а следовательно повышения производительности, неотъемлемым фактором которой является техникотехнологическая модернизация производства.

Безусловно, организация последнего на качественно другой, высокотехнологичной основе с использованием современных машин, техники и оборудования вызывают необходимость привлечения дополнительных инвестиций в агропромышленный комплекс в целом и подкомплекс мясного скотоводства в частности.

Однако не секрет, что инвестиции для аграрного сектора всегда являлись «слабым местом», тем более для такой отрасли как мясное скотоводство. Проблема состоит, мягко говоря, в инвестиционной малопривлекательности сельского хозяйства.

К сожалению, инвесторы и в целом отечественный бизнес не вкладывает средства в аграрный сектор по причине рискованности производства и достаточно продолжительного периода окупаемости. Даже банковский сектор неохотно идет на кредитование предприятий и организаций АПК, так как для них больший интерес представляют «короткие деньги».

В наших научных публикациях мы уже писали о хозяйственном механизме агропромышленного комплекса, одним из элементов которого является государственное регулирование товарно-денежных отношений в неординарных ситуациях, чтобы добиться сближения интересов и целей государства и хозяйствующих субъектов в реальном секторе экономики.

Нам представляется, что наиболее реальной и эффективной формой такого сотрудничества, ориентированного на сближение целей государства и бизнеса, является государственно-частное партнерство.

Такой экономический симбиоз при всех прочих равных условиях дает ряд серьезных преимуществ:

- в достаточно сложной экономической ситуации, в которой находится наше государство, когда санкционные меры ограничивают любого инвестора, концентрация средств создает си- 
нергетический эффект, а участие государства в любой форме является гарантом для инвестора и делает саму отрасль более инвестиционнопривлекательной;

- при этом создаются новые институты, то есть формируется институциональная среда, которая по своей сути и содержанию является инновационной;

- государственное участие может не всегда выражаться в денежных средствах, это могут быть земельные, водные, лесные и другие ресурсы;

- государство имеет реальную возможность участвовать в управлении системой партнерских отношений, в том числе осуществлять контролирующие функции, например, через органы казначейства.

В широком смысле государственно-частное партнерство - это перспективная форма сотрудничества государства и бизнеса на взаимовыгодной и равноправной основе [5].

В целом наращивание производства мяса КРС в некоторых регионах позволило сократить импорт замороженного мяса, но в то же время с 2010 по 2018 год наблюдается существенное увеличение импорта свежего-охлажденного мяса КРС (рисунок 2).

В соответствии с рекомендуемыми нормами потребления мяса КРС, утвержденными Минздравом России, норма потребления должна быть не менее 25 кг в год [8], но как видно из данных табл. 2, в Российской Федерации на душу населения потребление отстает более чем в 2 раза от рекомендуемых норм. Для сравнения в 2020 году потребление мяса КРС в Бразилии составило 24 кг, в США 26 кг, в странах ЕС около 15 кг.

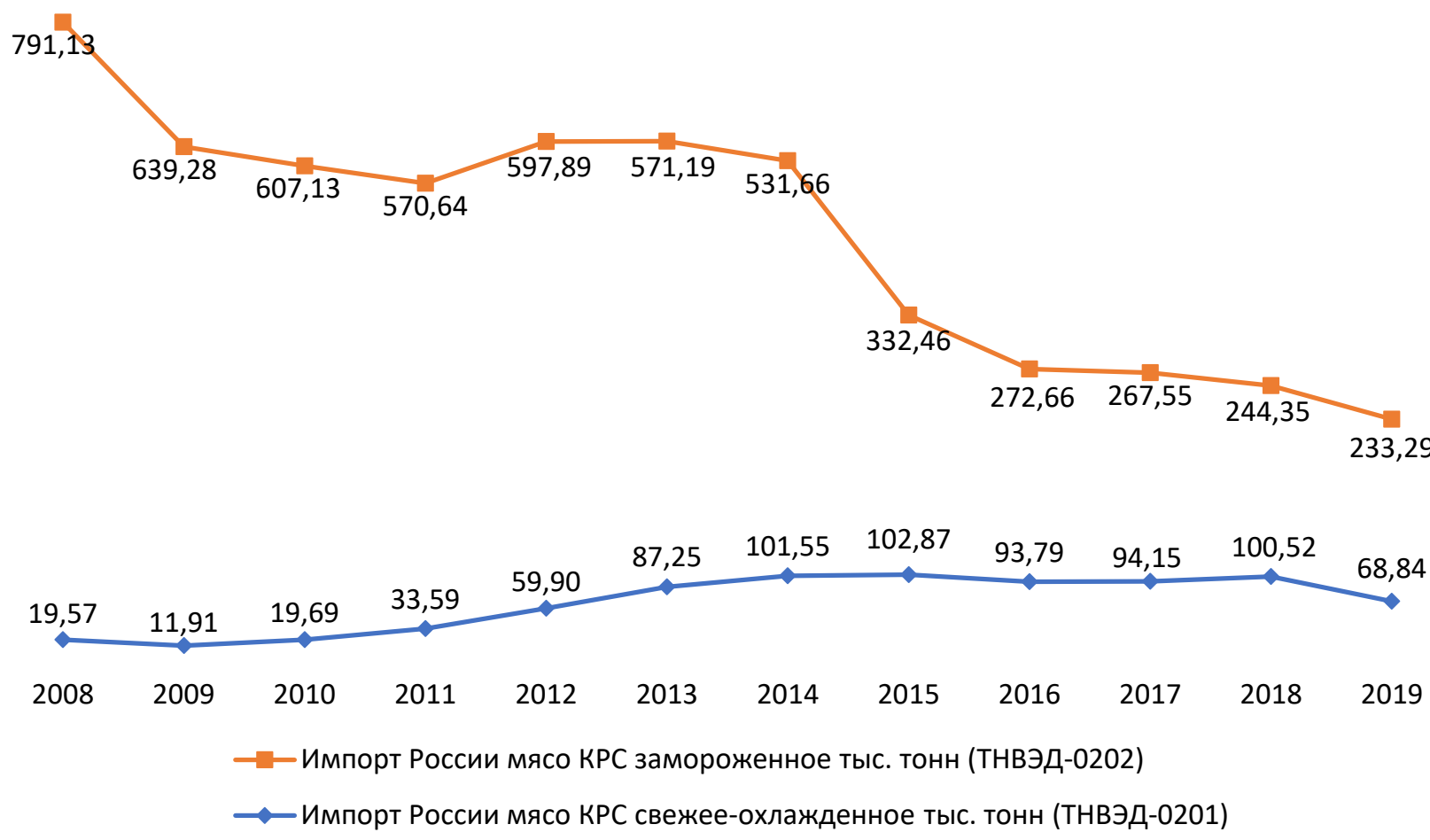

Рисунок 2. Импорт мяса КРС, тыс. тонн [6]

Таблица 2. Потребление мяса КРС в США, ЕС, Бразилии и России в 2000-2020 гг., кг на душу населения [7]

\begin{tabular}{|c|c|c|c|c|c|c|c|c|c|c|c|}
\hline & 2000 & 2002 & 2004 & 2006 & 2008 & 2010 & 2012 & 2014 & 2016 & 2018 & 2020 \\
\hline США & 37,0 & 31,1 & 30,3 & 30,2 & 28,7 & 27,3 & 26,1 & 24,6 & 25,3 & 26,1 & 26,2 \\
\hline ЕС & 15,9 & 15,8 & 15,6 & 15,5 & 15,1 & 14,7 & 14,2 & 13,8 & 14,1 & 14,5 & 14,4 \\
\hline Бразилия & 25,2 & 25,7 & 27,8 & 32,1 & 26,9 & 26,3 & 26,1 & 26,1 & 25,3 & 25,3 & 24,1 \\
\hline Россия & 10,3 & 11,9 & 12,1 & 12,1 & 14,3 & 12,6 & 13,9 & 11,9 & 10,1 & 10,0 & 10,0 \\
\hline
\end{tabular}

Источник: Организация экономического развития и сотрудничества // https://www.oecd.org/ 


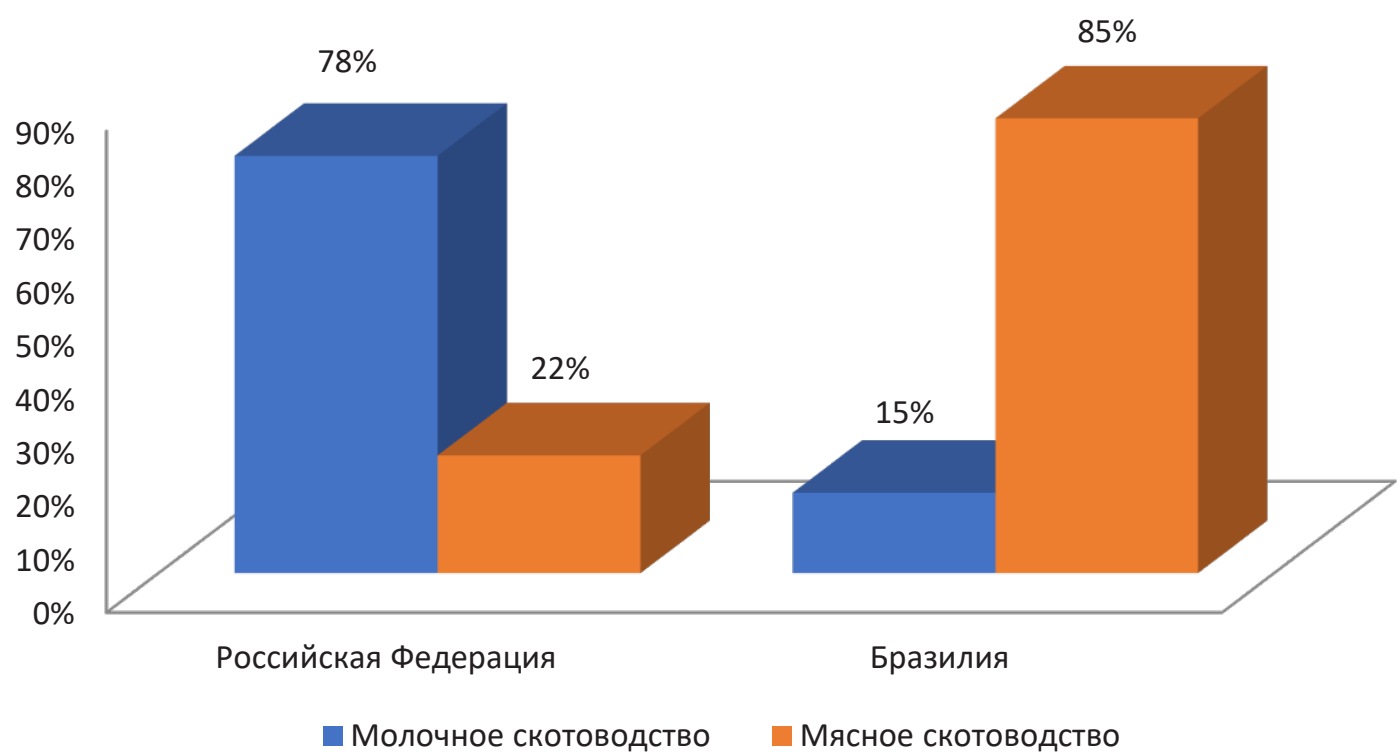

Рисунок 3. Структура стада КРС России и Бразилии в 2019 г.

Как видно из рисунка 3, одна из проблем, которая не позволяет в России достичь рекомендуемых медицинских норм потребления говядины является низкая доля мясных пород скота в структуре поголовья, тогда как в некоторых странах удельный вес мясных пород составляет 85\%.[9] Отдельные попытки отечественных агрохолдингов, таких как «Мираторг» в расширении породного мясного скотоводства имеют негативный характер, а для преломления сложившейся ситуации, требуется соответственная полномасштабная государственная политика в сфере развития мясного скотоводства, что требует колоссальных вложений в селекционные центры, племенные хозяйства и товарные хозяйства, специализирующихся на выращивании мясных пород скота.

Сегодня в мире накоплен достаточно обширный опыт в области обеспечения населения мясом крупного рогатого скота. Мы сошлемся на опыт Бразилии и рассмотрим возможность его экстраполяции на российскую реальность. За последние полвека Бразилия совершила переворот в организационной структуре АПК, что позволило ей не только увеличить результативность сельского хозяйства, но и в целом приблизиться к решению проблемы голода, а также стать крупнейшим мировым производителем и экспортером целого ряда видов сырья и продовольствия (от традиционных сахара и кофе до биоэтанола и соевых бобов). На этой основе было освоено около 50 млн. га, в основном в зоне саванн-серраду, немалую роль в развитии сельского хозяйства этой страны сыграл технико-технологические инновации.

Это позволило более чем в два раза увеличить валовой сбор зерновых и сои и почти трехкратному росту производства мяса. Эти достижения в большой степени стали возможными благодаря успешной деятельностьи созданной государством в 1973 г. Бразильской корпорации исследований в области земледелия и животноводства (Embrapa).

Embrapa - это институт финансируемый федеральным правительством Бразилии, входящий в систему Министерства сельского хозяйства и продовольствия. В ее состав входят 46 специализированных центров, построенных и оснащенных оборудованием за счет средств федерального бюджета. Центры строились в разное время и расположены в различных штатах страны, а также за ее пределами. Годовой бюджет компании в 2013 году составлял около \$1 млрд.

Успех деятельности центров во многом обеспечен тем, что они обладают финансовой автономией и работают по принципу государственно-частного партнерства, привлекая значительные объемы внешних инвестиций от фондов и правительств зарубежных стран, национальных и иностранных компаний агробизнеса до независимых агропроизводителей.

Внедрение результатов НИОКР Embrapa осуществляет через взаимодействие с партнерами: компаниями, производящими средства про- 
изводства для сельского хозяйства (удобрения и средства защиты растений, технику, семена), негосударственными фермерскими организациями, сельскохозяйственными кооперативами. Специалисты Embrapa зачастую выступают консультантами фермеров: автомобили с фирменным логотипом компании можно встретить на полях в любом уголке бразильской сельской глубинки. Таким образом, расширяются возможности для апробации и внедрения разработанных Embrapa технологий. По оценке руководства Embrapa, на каждый потраченный реал компания «возвращает бразильскому обществу 9 реалов в виде создания знаний, технологий и обес-печения занятости».

Особенностью ведения сельскохозяйственного производства Бразилии является тот факт, что более $80 \%$ занятых в отрасли не имеют собственной земли, в то время как $1,5 \%$ собственников владеют половиной всех сельскохозяйственных угодий. Эти крупные земельные владения - латифундии - играют главную роль в сельском хозяйстве: именно гигантские плантации латифундий производят продукцию на экспорт. Существуют и минифундии - небольшие фермерские хозяйства. Их доля в земельной собственности невелика, однако они производят основную часть продукции для внутреннего потребления. Несправедливое распределение земель, монополизация основного земельного фонда латифундиями и высокая арендная плата за землю часто приводят к конфликтам фермеров с властями и затрудняют процесс развития сельского хозяйства.

Кроме того, правительством Бразилии была представлена «Программа по сельскому хозяйству и животноводству 2018-1919», которая предусматривает выделение сектору немного больше ресурсов, чем 190,25 млрд. реалов $(50,06$ млрд. долларов США) в прошлом году. На период действия новой программы в бюджете зарезервировано до 194,3 млрд. реалов (51,13 млрд. американских долларов) в виде займов для содействия крупным и средним сельскохозяйственным производителям. Процентная ставка по кредитам составит 6\% для предприятий среднего размера и 7\% для остальных, тогда как ставки по инвестициям будут составлять от 5,25 до $7,5 \%$ в год.
Заключение. В результате проведенных исследований можно предложить следующие направления развития мясного скотоводства. В связи с введением новых правил субсидирования АПК в 2020 г., по условиям реализации Государственной программы развития сельского хозяйства и регулирования рынков сельскохозяйственной продукции сырья и продовольствия на 20132020 гг., где вместо единой региональной субсидии несвязанной поддержки предусмотрены компенсирующая и стимулирующая субсидии, по нашему мнению необходимо связать в большей степени с производством мяса КРС на основе изменения структуры породного состава и расширения поголовья мясного направления КРС. Учитывая достаточно длительный период, который потребуется для изменения и в целях активизации этого процесса представляется важным и необходимым стимулирование вложений частного капитала в формирование и создание передовых племенных, селекционных центров и ферм мясного направления, что будет способствовать решению проблемы удовлетворения потребности населения в этом виде продовольствия.

Одним из перспективных направлений выстраивания концепции развития мясного скотоводства является формирования двухуровневой системы развития мясного скотоводства и соответственного движения инвестиций, как это наблюдается в Бразилии, где крупные агрохолдинги конкурируют с малыми формами хозяйствования, объединенными на основе кооперации по сбыту продукции. В дальнейшем крупные формирования могут быть переориентированы на экспорт мяса КРС, малые же формы хозяйствования могут обеспечивать внутренние потребности страны, что будет способствовать частичному решению вопросов связанных с обезлюдением села и развитием сельских территорий, а также вопросов, связанных с решением проблемы импортозамещения мяса КРС. Такое взаимодействие крупного и среднего бизнеса с малым и микро- предприятием позволяет более рационально использовать имеющиеся инвестиционные ресурсы, высвобождая их в агрохолдингах и расширяя в сфере малого предпринимательства. 


\section{Библиографический список}

1. Указ Президента РФ от 21 января 2020 г. № 20 “Об утверждении Доктрины продовольственной безопасности Российской Федерации"

2. Трубилин И.Т. Сущность и особенности оценки экономической эффективности мясного скотоводства / Трубилин И.Т., Бершицкий Ю.И., Сайфетдинов А.Р. // Труды Кубанского государственного аграрного университета, 2013 г., № 44, С.25-32

3. Национальный доклад о ходе и результатах реализации в 2019 году Государственной программы развития сельского хозяйства и регулирования рынков сельскохозяйственной продукции, сырья и продовольствия».- М.: ФГБНУ «Росинформагротех», 2020.-180 с.

4. Национальный доклад о ходе и результатах реализации в 2019 году Государственной программы развития сельского хозяйства и регулирования рынков сельскохозяйственной продукции, сырья и продовольствия».- М.: ФГБНУ «Росинформагротех», 2020.-180 с.

5. Мазлоев В.З., Хайруллина О.И. Государственно-частное партнерство по технической модернизации мясного скотоводства // Экономика сельскохозяйственных и перерабатывающих предприятий. 2016. №9. С. 28-33.

6. Статистический отдел ООН по экономическим вопросам // https://comtrade.un.org/data/

7. Организация экономического развития и сотрудничества // https://www.oecd.org/

8. Приказ Министерства здравоохранения РФ от 19 августа 2016 г. № 614 «Об утверждении Рекомендаций по рациональным нормам потребления пищевых продуктов, отвечающих современным требованиям здорового питания» // https://www.garant.ru/products/ipo/prime/doc/71385784/

9. Опыт развития мясного скотоводства в Бразилии // https://meatinfo.ru/news/za-30-let-braziliya-iz-importeraprevratilas-v-eksportera-govyadini-400731

10. Мазлоев В.3. Адаптация хозяйственного механизма АПК к санкционным мерам // Экономика сельскохозяйственных и перерабатывающих предприятий. 2015. № 2. С. 28-31.

11. Национальная экономика и обеспечение продовольственной безопасности в условиях интеграции и глобализации / под ред. Э. Н. Крылатых, В. З. Мазлоева.- М.: ИНФРА-М, 2015.-240с.

12. Хаирбеков А.У., КибировХ.Г. Инвестирование в агропромышленное производство на принципах государственно-частного партнерства // Теория и практика мировой науки. 2018. № 2. С. 8-12. 